\title{
Los museos de cerámica en España. Investigación y difusión
}

\author{
J. COLL CONESA \\ Museo Nacional de Cerámica "González Martí". Valencia
}

\begin{abstract}
Los museos de cerámica en España han sufrido un notable impulso en los últimos años. A los grandes centros se ha sumado museos municipales y privados con nuevos planteamientos. Sus propuestas ofrecen nuevas perspectivas y auguran buenos resultados tanto por el incremento en la investigación como en su acción educativa.
\end{abstract}

Palabras clave: Museos de cerámica, España, investigación, difusión.

Ceramic museums in Spain. Research and Communication.

Ceramic museums in Spain had received a vigorous impulse in recent years. The cultural offer of the biggest, had been increased lastly by those of the small county museums and private centres with innovative perspectives. New proposals and experiences augur a major educative improvement, based on more recent research and efforts to communication.

Key words: Ceramic museums, Spain, research, communication.

\section{INTRODUCCIÓN.}

En el presente artículo se trata de exponer brevemente el papel de los museos como centros de investigación y difusión de la cerámica. Se analizan, de forma general, los museos monográficos de cerámica institucionalizados, tanto de titularidad pública como privada, mencionando también aquellos no monográficos que pueden considerarse representativos en este campo. Por razones de espacio no se incluirán los museos provinciales o arqueológicos con buenas colecciones que no se encuentran volcados exclusivamente hacia el campo de la cerámica, que en todo caso se citarán puntualmente en función de su interés particular.

El origen de muchos de estos museos debe buscarse en el coleccionismo de cerámica iniciado en las últimas décadas del siglo XIX, paralelo a los comienzos de su estudio histórico. En particular se citan aquí los casos de D. Guillermo J. de Osma, fundador del Instituto Valencia de Don Juan, de Don Platón Páramo o D. Juan Ruiz de Luna Rojas, promotores del Museo de Cerámica de Talavera, de D. Manuel González Martí, en el caso del Museo Nacional de Cerámica, o Enrique Batlló i Batlló, P. Moncada, S. Rocamora, Josep Ma . Roviralta y Antoni Coll Fort, coleccionistas que legaron o vendieron sus colecciones al Museo de Cerámica de Barcelona. Otros casos se relacionan además con la propia producción cerámica de los fundadores de los mismos como en los casos de los Ruiz de Luna, en Talavera, y Zuloaga, en Segovia.

Más recientemente, en especial a partir de los estudios de la alfarería española que tuvo su auge en la década de los años setenta, se formaron otras colecciones privadas de importancia muchas de las cuales se han integrado ya en museos públicos (Donación Knecht-Drenth al Museo Nacional de Antropología), mientras otras se encuentran en ese camino, como es el caso del Museo de Alfarería de Agost, o formando parte de los fon- dos estables de museos privados, como ocurre con la colección Sempere, germen del Museo de Cerámica Popular de l'Ametlla de Mar de la Fundación Privada Martí Castro, o J. M. Kaydeda en Os Oleiros. Ultimamente el número de instituciones especializadas de este tipo se ha incrementado enormemente, planteando nuevas propuestas en cuanto al papel del museo y su organización, como ocurre con el Museo de Alfarería de Ollerías, donde no sólo se expone la cerámica sino que funciona al tiempo como taller activo a la vista del visitante.

Por otra parte, en muchos lugares donde ha habido asentamiento tradicional de industria cerámica, se observa la tendencia de preocuparse del pasado artesano o industrial. En esta línea se han potenciado los museos de La Bisbal, Manises, Onda, Alcora, Paterna, y la colección museográfica de Potries. Existen otros casos donde determinadas tradiciones festivas han sido las impulsoras de centros museológicos, como ocurre con el Museu del Càntir de Argentona.

De todo ello se hace una valoración muy positiva, debido a que este esfuerzo ha contribuído de manera muy notable a potenciar la investigación de la historia y antropología de la cerámica, así como las actividades de difusión acerca de este patrimonio, aún a pesar de las dificultades que muchos de estos museos tienen para desarrollar su labor, en especial debido a las limitaciones de medios y personal, que son suplidas con una gran dedicación por parte de sus responsables.

La actividad generada por estos centros está siendo fundamental por las nuevas aportaciones en cuanto a organización de cursos o ciclos de conferencias, exposiciones, labor editorial de divulgación o investigación, incluso dando sus primeros frutos en el mundo de la edición en formato CD-ROM del que ha sido pionero el Museo de Alfarería de Ollerías. Sería prolijo aquí enumerar todo lo realizado por cada uno de los centros, 
por lo que se aborda este aspecto centrándose en el último decenio, de forma que esta aportación sea una breve guia para aproximarse a sus diversas actividades.

Una mención especial merece la investigación arqueológica desarrollada por algunos museos de cerámica que pueden considerarse como "museos de sitio", como es el caso del Museo de Paterna o el Museo de Cerámica de Manises. Ambos han generado un volumen de información altamente valiosa para el reconocimiento de las producciones, de las tecnologías de fabricación y de los talleres del pasado, la cual ofrece visiones novedosas, nuevos argumentos para la investigación y un mejor conocimiento del pasado de esta tradición técnica. En este sentido además, la investigación de los servicios arqueológicos urbanos puede encontrar un cauce adecuado de difusión de sus resultados gracias al apoyo que pueden prestar los museos especializados en cerámica, primeros centros interesados en la difusión de las novedades que pueden ofrecer.

Se puede plantear si realmente son necesarios los museos de cerámica. La respuesta no puede ser más que afirmativa ya que en la museografía de hoy, lo mismo que ocurre en nuestra sociedad, existe una tendencia hacia la especialización de la cual el hecho del aumento de museos específicos constituye una evidencia más. Además existen otras razones que atañen a la necesidad de un conocimiento más y más profundo de las realidades históricas, tecnológicas y sociales visibles a través de nuestras colecciones, lo cual exige en la explicación de cualquier evidencia material del pasado o del presente, una mayor información, paralela a un discurso más extenso y amplio en las propuestas museográficas. Este hecho introduce la necesidad de la pluridisciplinariedad en las opticas de investigación $\mathrm{y}$, evidentemente, en los discursos museográficos de nuestras colecciones. Al mismo tiempo, los mayores conocimientos de los que ahora se disponen exigen también más espacio para su explicación, siendo así que sólo la creación de nuevos museos o la ampliación de los existentes pueden satisfacer estas necesidades.

¿Cuál puede ser el interés intrínseco de la cerámica desde una perspectiva histórica?. La cerámica es básicamente un material cotidiano usado por todas las sociedades desde el orígen de la civilización humana. Hace ya tiempo que la arqueología la valoró como un elemento básico para aproximarnos a la seriación de la cultura material desde el neolítico a nosotros, dadas sus cualidades de casi eterna pervivencia. Sin embargo, a medida que las disciplinas implicadas en su estudio y por ende las perspectivas adoptadas en su análisis aumentan, el potencial informativo del material crece en proporción geométrica.

La cerámica refleja mejor que casi ningún objeto los cambios de la sociedad, desde el modelo económico y el comercio a las costumbres cotidianas, las necesidades técnicas, las fases de carencia u opulencia, al igual que ofrece indícios de procesos de migración, colonización, etc. El museo de cerámica debe ser capaz así de asumir un nuevo reto, el de pasar de ser un centro estático donde las cerámicas se muestran a partir de sus coordenadas esenciamente estéticas, a comunicar los procesos técnicos, económicos, históricos y sociales que su estudio nos puede deparar, además de deleitarnos con su belleza intrínseca. Todo ello es asumible a partir de su análisis y exhibición desde una perspectiva global con el concurso de todas las ópticas, todas las técnicas y todos los puntos de vista que puedan ser requeridas.

Cabe hacer sin embargo una reflexión final, y es la de plantearse con mirada crítica si nuestros museos de cerámica están suficientemente dotados de medios materiales y humanos para desenvolverse en el futuro satisfaciendo las necesidades de nuestra sociedad. Los museos deben asumir el reto de enseñar a las generaciones presentes, y trasmitir a las futuras, el inmenso peso que la cerámica tuvo en el día a día del pasado, al tiempo que ser capaces de escrutar los nuevos horizontes que la sociedad demanda a este producto que ha acompañado a la civilización desde sus orígenes.

En estas líneas se debe inscribir la actuación de los museos de cerámica de hoy. No existe ningún centro que pueda constituirse como el museo total, exponente de todos estos procesos. Cada centro ha buscado abrir brechas en nuevos planteamientos, iniciar caminos o aumentar las experiencias como mejor ha podido a partir de su tradición, de sus experiencia y de sus medios. A continuación se esboza la situación actual experiencias en los principales museos especializados del país, y sin duda el análisis de sus realidades actuales permitirán conocer su papel en la investigación y difusión.

\section{MUSEOS DE CERÁMICA EN ESPAÑA. REALIDADES, EXPERIENCIAS Y CAMINOS EN LA INVESTIGACIÓN Y DIFUSIÓN.}

Los museos de cerámica en España constituyen un conjunto de entidades de naturaleza heterogénea tanto en cuanto a su dependencia administrativa, su organización, la naturaleza de sus fondos y su experiencia, entre otros factores. Se puede proceder a la descripción de sus principales características y logros a partir de su dependencia administrativa, aunque ello no implique ulteriores rasgos en cuanto a sus planteamientos teóricos, funcionamiento o vitalidad. Sí cabe hacer algunas aproximaciones generales como que los grandes museos históricos, tanto nacionales como provinciales o municipales son en general grandes contenedores de colecciones históricas, los museos municipales de reciente creación están más próximos a la investigación histórica y arqueológica de base, y que los museos particulares, básicamente de alfarería, son creaciones recientes que han intentado romper con el modelo tradicional de colección para abordar retos de investigación y difusión desde planteamientos de defensa de la artesanía o de conocimiento del "arte popular".

Veamos cuáles son las realidades, características y experiencias de los principales museos y colecciones públicas de cerámica en España agrupados por su dependencia administrativa.

\section{A/ MUSEOS DEPENDIENTES DE ORGANISMOS DEL ESTADO, COMUNIDADES AUTÓNOMAS O ENTES PROVINCIALES.}

\section{-Museo Nacional de Cerámica y de las Artes Suntuarias.}

El Museo Nacional de Cerámica González Martí nació por Orden Ministerial de 7/2/1947 por donación al Estado de la Colección de cerámica de D. Manuel González Martí y Doña Amelia Cuñat. Durante unos años, el museo tuvo su sede en el domicilio particular del fundador. Entre esa fecha y 1954 el director-donante realizó gestiones primero para adquirir un inmueble para el Museo, y luego para la adecuación del mismo. Se escogió para ello el Palacio del Marqués de Dos Aguas, a la sazón en estado de abandono, realizándose una profunda intervención y remodelación, que pudo inaugurarse el 18 de junio de 1954. La superficie actual del edificio es de unos $8000 \mathrm{~m}^{2}$.

El Museo Nacional de Cerámica nació con voluntad de cons- 
tituirse en el museo de la cerámica española, dada la reconocida tradición de los centros valencianos de Manises y Paterna. Sin embargo, por lo emblemático del propio edificio y de parte de los fondos históricos relacionados con él, con importantes colecciones de mobiliario, hicieron que desde un principio el museo no se considerase como institución monográfica, sino representativa también de las artes suntuarias de la región valenciana. La aceptación de esta realidad llevó a la ampliación del título del museo en 1969 que pasó a denominarse "Museo Nacional de Cerámica y de las Artes Suntuarias "Gonzalez Martí".

El Museo, por tanto, se organizó sobre dos ideas básicas:

- Servir como exponente de la cerámica histórica española a partir principalmente de los fondos valencianos recopilados por D. Manuel González Martí que, como él mismo comenta, eran limitados sólo en función de los medios personales dispuestos en la formación de la colección.

- Devolver al Palacio de los Marqueses de Dos Aguas la riqueza original recuperando su ambientación interior y arropándola con elementos suntuarios arraigados en la zona, tanto de mobiliario, pintura, indumentaria, armamento, etc.

Estas dos líneas básicas pronto se ampliaron con la adición de fondos relacionados con personajes relevantes de la región (El compositor Giner, los hermanos Capuz y García Oliver, familias Pinazo y Benlliure, Giacomo Lauri Volpi y Maria Ros, Vicente Blasco Ibáñez, Manuela Ballester y tantos otros). Por lo dicho es evidente la heterogeneidad de los fondos que conserva el Museo.

En cuanto a personal, el museo tiene una estructura orgánica mínima de personal en plantilla (funcionarios y contratados laborales), para desarrollar su actividad.

El museo cerró sus puertas en 1990 para renovar sus instalaciones, dados los problemas que presentaban y lo obsoleto de su discurso expositivo. Durante estos años, el museo se ha centrado en la catalogación de sus fondos y en la preparación del futuro.

En cuanto a investigación de base, el Museo ha participado en cinco excavaciones arqueológicas (Alcalá del Júcar, Meca y Manises, C/ Valencia, 90, horno de Algar de Palancia y Palacio de Dos Aguas), tres sobre hornos de cerámica, una sobre un testar medieval de Manises y otra sobre el mismo palacio en rehabilitación. Por otra parte, desde 1988 se encuentra incorporado a un proyecto de investigación con instituciones portuguesas sobre intercambio comercial y estético de la cerámica entre España y Portugal. Además de esto, se han realizado informes sobre hallazgos de conjuntos cerámicos de interés y numerosas comunicaciones a congresos, libros de divulgación, y catálogos de exposiciones. Desde 1990 participa conjuntamente con el Museo de Manises en la sistematización de formas y decoraciones de la cerámica de aquella localidad. Para ello se ha construído un sistema de bases de datos auxiliares de la catalogación. Una de las líneas abiertas es la arqueometría cerámica, con tres aportaciones realizadas, dos sobre tecnología de fabricación y una de caracterización de materiales aplicada a la restauración. El museo ha apoyado además la restauración y conservación preventiva en proyectos ajenos.

Una de las principales funciones educativas del museo se ejerce a través de la exposición, hasta el punto que en el sentir general, independientemente de lo reclamado en los foros propios de la museología, el museo es básicamente un lugar donde se exhiben objetos. En el antiguo montaje expositivo, en realidad una réplica de la colección histórica del domicilio del fundador, la inmensa fuerza de la instalación museográfica con la riqueza de ambientaciones y la saturación de obras expuestas restaba importancia final a lo esencial, predominando el deleite sobre la educación. En el futuro nos planteamos conseguir un equilibrio dedicando unas zonas del palacio a la reconstrucción de ambientaciones históricas y otras, aquellas con menor peso ornamental, a la generación de salas sistemáticas con los objetos esenciales para exponer un discurso. Para mantener viva la función expositiva aún con el museo en plena rehabilitación, se muestra desde 1994 en la Sala de la Muralla del Instituto Valenciano de Arte Moderno una exhibición con una selección de 200 cerámicas.

En 1985 se inició una importante actividad en el campo de la difusión educativa por parte del Gabinete de Didáctica. Las ocasionales colaboraciones a través de contratos del INEM le dieron notable vitalidad. Sin embargo, por problemas de personal, desde 1990 se redujo su actividad.

En cuanto a exposiciones cabe mencionar las realizadas por el Museo para divulgar sus fondos o la obra de artistas contemporáneos. Las exposiciones de producción propia (Cerámica y Cambio Cultural, Fondo Bibliográfico Antiguo) han sido sucedidas por otras de fondos inéditos de instituciones colaboradoras (Cerámica Califal de Benetússer, Cerámica de Daniya), en parte debido a las prioridades internas que han reclamado la atención de los técnicos de la casa en otras labores (realización del inventario, gestión de fondos), y por los problemas generados por las obras de rehabilitación sufridas estos años (preparación de espacios para almacenamiento, traslado de todos los fondos, etc.). Ocasionalmente se han ofrecido exposiciones itinerantes de otras instituciones (Cerámica de Faenza, Muñecas del Japón), o se ha colaborado en montajes externos (Le Vert et le Brun), generalmente no a título institucional.

La línea editorial, interrumpida desde 1995, ha permitido que salieran a la luz el catálogo de la Indumentaria femenina del museo y un estudio sobre loza medieval hallada en Valencia.

El museo ofrece una excelente biblioteca abierta al público que tiene como objetivo reunir en principio la producción editorial española sobre cerámica, así como obras de referencia para el estudio de las colecciones.

La previsión para abrir nuevamente las puertas, una vez terminada la rehabilitación del Palacio, es hacia diciembre de 1999.

\section{- Museo de Cerámica de Zaragoza (sección del Museo Provincial).}

Abierto al público en 1991 en uno de los pabellones del Parque regional de Zaragoza reproduciendo una típica casa de la Sierra de Albarracín, depende del Museo de Zaragoza, con una superficie de exposición de unos $600 \mathrm{~m}^{2}$.

En cuanto a su exposición el museo se concibió como un compendio de la cerámica aragonesa. La planta baja se dedica a explicar las funciones que realiza la cerámica en una doble coordenada funcional y temporal, introduciendo un punto de vista antropológico. La planta primera y segunda muestran las producciones históricas de cerámica fina aragonesa, sin descuidar la comparación con objetos contemporáneos de otras zonas, por talleres y cronología. La última planta presenta una visión de la alfarería aragonesa.

El museo en sí dispone de escasa dotación de personal exclusivo por pertenecer su plantilla al Museo Provincial de Zaragoza. Carece de actividad propia, excepto la necesaria para cubrir la función expositiva, cuyo concepto nació de un intenso estudio realizado al plantear su proyecto museográfico. 


\section{- Museo de Cerámica "Ruiz de Luna" (Talavera).}

Se trata de la antigua colección Ruiz de Luna adquirida por el Estado. Administrativamente el Museo es un anexo del Museo de Santa Cruz de Toledo. En él se exhiben cerámicas locales de Talavera y Puente, así como otras realizadas por el taller de los Ruiz de Luna, con un criterio de seriación sobre la base de las hipótesis planteadas sobre la evolución cronológica de las producciones.

No posee dotación específica de personal y medios, excepto el esencial subalterno, sin embargo la existencia de la Asociación de Amigos dinamiza la institución mediante la pubicación de la revista "Alizar abierto" y, en especial, la organización de numerosas exposiciones temporales.

\section{- Museus de Martorell (Memorial Ros y Museu de l'Enrajolada).}

Actualmente gestiona los antiguos museos Museo Municipal Vicente Ros, Memorial Ros y el Museo Provincial L'Enrajolada, todos con muy notables colecciones de azulejería catalana y valenciana. Ocupan unos $2500 \mathrm{~m}^{2}$. Son gestionados por un patronato conjunto formado por el Ayuntamiento de Martorell y la Diputación de Barcelona. Albergan la colección Ros de azulejería, y numerosos elementos arquitectónicos, de azulejería y cerámica de los siglos XIV al XX, además colecciones de pintura, mobiliario, elementos arquitectónicos y ajuar doméstico.

Se encuentran en remodelación desde hace varios años, habiéndose generado en ellos una gran experiencia en restauración e instalación de azulejos sobre autoportantes.

\section{B/ MUSEOS DE DEPENDENCIA MUNICIPAL.}

\section{- Museo de Cerámica de Barcelona:}

Se encuentra instalado de forma provisional en el Palacio de Pedralbes, ocupando un ala de la residencia de la familia Real en Barcelona. Sin embargo parece que esta ubicación va a ser definitiva existiendo proyectos para su ampliación. La superficie que ocupa actualmente es de unos $4000 \mathrm{~m}^{2}$.

En cuanto a concepto, se trata de un museo monográfico centrado en la cerámica de valor decorativo, con muy buena representación de la cerámica española en general, en especial de la Catalana, Valenciana, Aragonesa y Castellana de Talavera y Puente del Arzobispo, abarcando cronológicamente del medioevo (siglos XII-XIII) a la actualidad. Son excepcionales su colección de Alcora y de cerámica medieval valenciana.

En cuanto al desarrollo de las funciones museográficas cuenta con personal cualificado, tres técnicos superiores, equipo de restauradores y numeroso personal de administración y subalterno.

La exposición se realiza en la planta noble del edificio, donde se exponen con un criterio geográfico y cronológico las diferentes colecciones. En la última planta se reúne la cerámica contemporánea.

En cuanto a la investigación, posee una buena biblioteca y su personal técnico está compuesto por Historiadoras del Arte que centran su investigación en aspectos estéticos. Mantiene numerosos contactos internacionales lo que facilita la frecuente organización de exposiciones que aúnan los intereses de centros de distintas nacionalidades (Cerámica de Faenza, El reflex de Manises, Miró Ceramista, etc.).

En cuanto a la difusión, cabe decir que el museo organiza cursos de formación en historia de la cerámica y en restauración, así como numerosas conferencias. Los mismos conservadores se ocupan de las actividades de didáctica. En los últimos años ha presentado excelentes exposiciones con valiosos catálogos. Ha publicado también el catálogo de la colección del museo.

\section{- Museu Municipal de Cerámica de Manises.}

Denominado oficialmente "Museo Municipal Casanova Dalfo-Sanchis Causa", apellidos de los donantes del edificio y de las primeras colecciones, se ubica en una casa del siglo XVIII que ha sido ampliada en 1986 . Ocupa una superficie de unos $2000 \mathrm{~m}^{2}$

El museo expone las producciones históricas de Manises desde época medieval hasta el siglo XX. Reúne también una sección didáctica centrada en explicar los principios de la tecnología cerámica y diversos equipos mecánicos utilizados para este fin. Uno de sus objetivos, de cara a su ampliación, es la creación de un Ecomuseo con algunas de las fábricas tradicionales del sector histórico que subsisten en pié.

Realiza todas las funciones que cabe esperar de un museo. En investigación su labor se centra en la recopilación y documentación de los testimonios industriales de Manises, coordina las excavaciones arqueológicas de urgencia, colaborando ocasionalmente con personal del Museo Nacional de Cerámica. Fruto de su investigación son numerosos trabajos sobre la cerámica de Manises del siglo XVIII, alfarería valenciana y la loza de reflejo metálico de los siglos XIX y XX. Produce sus propias exposiciones, alguna de las cuales se ha ofrecido además en el centro Cultural de la Beneficencia de Valencia. Ha iniciado una línea de arqueometría cerámica en colaboración con la Escuela de Cerámica de Manises y la Universidad Politécnica de Valencia. Lleva a cabo un proyecto de investigación sistemático sobre sistematización de la tipologia y de los elementos decorativos de la cerámica medieval.

Cuenta con Biblioteca, sala de exposiciones temporales, zona de administración, sala didáctica polifuncional, almacenes y un pequeño taller de restauración.

\section{- Museo Municipal de Cerámica de Paterna.}

Creado en 1980 a partir de los fondos del coleccionista Rafael Alfonso Barberá, se ocupa principalmente de las actuaciones urbanas de urgencia y de la excavación de los antiguos alfares medievales.

Funciona en realidad como centro de investigación especializado en la excavación arqueológica de los alfares medievales y del casco urbano municipal. Dispone de una exposición abierta al público. Actualmente se encuentra en fase de remodelación, mientras su actividad se centra en la investigación arqueológica, incrementando sus fondos mediante la realización de excavaciones arqueológicas. Realiza tareas de difusión, con exposiciones que atraen a un numeroso público del entorno. Tiene una línea editorial muy extensa. Desde hace algunos años colabora en la investigación arqueométrica conjuntamente con el Departament de Cristalografía de la Universidad de Barcelona.

\section{- Museu de Terrissa de la Bisbal.}

Instalado en una antigua fábrica de cerámica de grandes dimensiones es un centro de reciente creación.

El museo tiene vocación de convertirse en el museo catalán 
de la alfarería, aunque entre sus fondos conserva producciones alfareras de numerosos talleres de España, incluso alfarería extinguida. Otra vertiente debida a su ubicación, es la de museo industrial de la cerámica, exponiendo maquinaria y técnicas tanto de los procedimientos artesanales más sencillos hasta equipamientos de la industrialización.

El centro dispone de personal técnico para su funcionamiento. Organiza numerosas exposiciones sobre ceramistas de la localidad, técnicas de elaboración, utillaje, y dentro de una línea de recuperación y divulgación del lenguaje del sector, edita unos carteles con nomenclaturas que a su vez explican el funcionamiento de los equipos industriales así como la revista especializada "TREMP". Mantiene una exposición permanente con parte de los fondos de la colección de alfarería, y organiza talleres sobre técnicas de restauración. Se encarga también de recuperar para el Museo de documentación y materiales de las fábricas que van desapareciendo en su entorno.

\section{- Museo de Cerámica de Onda.}

La reestructuración del antiguo Museo Histórico Municipal creado en 1968, ha potenciado el desmembramiento de una parte de sus colecciones bajo esta denominación, mientras el resto funciona como museo arqueológico y se ubica en el Castillo. La superficie que ocupa es de unos $600 \mathrm{~m}^{2}$.

La relevante historia cerámica de Onda, de la cual conocemos indicios del s. $X$, demostró que era necesaria una especialización del museo local en este sentido. La principal orientación del museo, en parte recogiendo parte del ideario del antiguo museo histórico, se centra en la recuperación del patrimonio cerámico inmediato en vías de desaparición por los cambios urbanísticos, así como en la documentación de las industrias locales que todavía subsisten con medios tradicionales. Posee magníficas colecciones de azulejería local pudiendo convertirse en un centro especializado en cerámica arquitectónica.

El museo apenas acaba de iniciar su funcionamiento con dotación de personal y medios para su desarrollo. Se encuentra en fase de definición y organización. Ha realizado alguna exposición monográfica sobre cerámica encontrándose en fase avanzada su catalogación, al tiempo que desarrolla una buena política de adquisiciones. Tiene un buen apoyo de la industria local y su presencia en ferias y certámenes comerciales (CEVISAMA) es intensa. Fruto de su primer proyecto de investigación ha sido la publicación de un trabajo sobre las fábricas locales de los siglos XIX y XX. Actualmente elabora el proyecto museológico/museográfico y arquitectónico de una futura sede que permitiría regularizar su actividad, junto a un proyecto de valoración del entorno industrial con la creación de un ecomuseo.

\section{- Museo de Alcora.}

Desde hace pocos años (1994) existe el museo de Alcora, instalado en un inmueble de 1907 que conserva notables revestimientos de cerámica aplicada. Cuenta ya con personal técnico de plantilla y exhibe una buena colección de cerámica de Alcora, con algunas obras procedentes de depósitos del Museo de Cerámica de Barcelona.

En su sede, en vías de ampliación, exhibe una colección pequeña pero interesante de la producción histórica, además de las obras galardonadas en los certámenes que convoca anualmente el ayuntamiento y las exposiciones que organiza el centro, a veces producto de convenios o de investigación propia (cántaros, cerámica funeraria de Alcora). Difunde regularmente sus fondos e instalaciones en diversos foros, en especial CEVISAMA, junto al museo de Onda, manteniendo vinculaciones con la industria local. Ha iniciado investigaciones arqueológicas y en arqueometria cerámica.

\section{- Museu del Càntir de Argentona.}

Creado en 1975 por donación de un coleccionista de botijos, se ubica en una casa gótica. Depende del Ayuntamiento de Argentona y su fundación se relaciona con la antigua tradición local de bendecir el agua de los cántaros en la fiesta de Santo Domingo de Guzmán, en agosto. Esta tradición llevó a la organización del festival del cántaro en 1951 ahora coordinada desde el Museo. Ocupa una superficie de unos $400 \mathrm{~m}^{2}$.

La exposición del museo evidencia la relación entre la cerámica y el agua a lo largo de la historia, de todas las épocas y culturas que ha podido documentar, desde griegas, romanas, medievales a actuales, incluso de otras etnias como la bereber. Sirve de vehículo para la celebración del festival del cántaro y toma parte activa en la organización de la celebración. Su colección principal la forman cántaros y botijos de la alfarería popular española, pero contiene también piezas de funciones similares en otros materiales.

La dotación de personal es pequeña por lo que las actividades son limitadas. Además de la exposición, su principal función es articular la "Festa del Càntir", costeando anualmente la fabricación de miles de botijos de un alfarero o centro determinado que se venden posteriormente en la fiesta y son a su vez un medio importante de financiación. Organiza también un concurso de diseño. Dentro de las actividades de difusión e investigación, realizó una base de datos de producciones en video o sistemas audiovisuales sobre la cerámica española. Actualmente ha iniciado la reforma del edificio.

\section{- Colección municipal "Museo de Alfarería de Ubeda".}

Centro de muy reciente creación acogido en los sótanos del Ayuntamiento de Ubeda. Está formado por la cesión temporal de la colección de Juan "Tito", alfarero local, y por otros fondos propiedad del Ayuntamiento. Funciona gracias a la ayuda de la escuela Taller de Ubeda. La exposición abarca unos $600 \mathrm{~m}^{2}$. mientras los servicios son comunes con la Escuela Taller radicada en el mismo edificio.

La exposición muestra alfarería popular española, reuniendo una notable colección, en donde destacan las lozas andaluzas, numerosa alfarería desaparecida y objetos procedentes de reformas de edificios locales.

El personal propio se reduce a la función expositiva. Durante un cierto tiempo el museo y la Escuela Taller compartían un módulo de cerámica donde se enseñaban las técnicas actuales y tradicionales. Una de las actividades que emprendió, ahora abandonada, era la de salvaguardar los testimonios materiales de los talleres del barrio alfarero, con construcciones de varios cientos de años de antigüedad conservadas en muy buen estado.

\section{Colección Museo de alfarería de Potries.}

Colección municipal instalada en una antigua alfarería que conserva toda la infraestructura del inmueble. Custodia además una pequeña colección de alfarería local. Acaba de iniciar sus andaduras. 


\section{C/ MUSEOS PARTICULARES.}

\section{- Museo de Alfarería de Agost.}

Museo con una gran actividad, propiedad de la Sra. Ilse Schütz. El fundador de la colección fue Facundo Senpau. Se encuentra instalado en una antigua alfarería en el barrio alfarero creado en el siglo XIX. Se trata en realidad de un museo de sitio. Instalado en una alfarería que mantiene incluso los hornos, ilustra los productos locales tradicionales, aspectos de la historia local alfarera y las técnicas y procedimientos de fabricación.

Cuenta con escaso personal (Directora, Ayudante y colaboración ocasional de personal externo), desarrollando sin embargo un ingente trabajo en las tareas básicas de exposición, investigación y difusión. No tiene dependencias especializadas en conservación, pero dispone de un anexo, el Centro Agost de Investigación Alfarera, que es en realidad una fábrica con las instalaciones completas, que se ofrece con un módico alquiler a aquellas personas o instituciones que lo soliciten. Dispone también de apartamentos en alquiler. En realidad ofrece una buena infraestructura para aquellos que deseen reunirse en sesiones de trabajo para experimentar o intercambiar conocimientos sobre la cerámica.

Su investigación y su acción educativa es muy dinámica. Se ha centrado especialmente en la alfarería local, la alfarería femenina, la cerámica de Biar, coincidentes generalmente con exposiciones y publicaciones. Ha organizado algunos seminarios y congresos nacionales e internacionales, así como cursos $\mathrm{o}$ actividades de formación de todos los niveles.

\section{-Museo de Cerámica Popular. L'Ametlla de Mar.}

Se trata de un proyecto de la Fundación Martí Castro, la cual posee una colección extensísima de alfarería española. Ha construído un edificio de unos $2000 \mathrm{~m}^{2}$ que almacena más de 5.000 piezas de alfarería, concebido como el núcleo de un parque temático. En la fundación se ha integrado últimamente el Ayuntamiento local, lo cual da visos de continuidad futura por su vinculación pública a un proyecto inicialmente privado. Posee personal técnico para el funcionamientro del centro, tanto asalariado como por convenio.

En el presente año ha organizado el III Congreso de la Asociación de Ceramología.

\section{Museo de Ollería.}

Situado en Ollerías (Elosu, Alava), se construyó en una alfarería rehabilitada que mantiene una exposición abierta, con actividades centradas en la educación y difusión. Institución muy dinámica en estos aspectos, acaba de editar el primer CD-Rom sobre alfarería de España, centrado sobre la alfarería vasca.

\section{Museo de alfarería Basilio Sobrecueva.}

El museo se asienta en un caserío restaurado a las afueras de Cangas de Onís. Exhibe una excepcional colección de alfarería asturiana, financiándose a partir de servicios comerciales como tienda y cafetería. Ha organizado algunas exposiciones de alfarería local, pequeños folletos y también el II Congreso de la Asociación de Ceramología.

\section{Museo de Cerámica Nacional de Chinchilla.}

Colección con fondos significativos reunida por un grupo de entusiastas reunidos en la asociación "Museo de Cerámica la Peñuela de Chinchilla" que acoge una importante muestra de la producción local, además de otra alfarería española. Gracias al empuje de D. Manuel Belmonte y $\mathrm{D}^{\mathrm{a}}$ Carmina Useros el museo abrió sus puertas en 1980. Excepto la función expositiva, no realiza investigación ni dinamización cultural.

\section{Museo de los Molinos Gregorio Prieto de Valdepeñas.}

La colección tinajera que contiene le vincula con la alfarería. En 1997 organizó las 1as. Jornadas sobre la Alfarería, con la tinaja como tema central.

\section{Museo Os Oleiros.}

José María Kaydeda, su fundador y director, recopiló una extensa colección de alfarería española y portuguesa que ahora, merced de un acuerdo alcanzado con el Concello de Os Oleiros (A Coruña), se encuentra exhibida en el Pazo de las Torres de Santa Cruz. En el edificio se instala parte del equipamiento cultural de la localidad conjuntamente con la colección de alfarería. El museo organiza la feria de alfarería local en los meses de verano, a la cual suelen invitar a artesanos de distintos centros. La exposición se ordena por centros alfareros y presenta tanto producciones actuales como desaparecidas.

\section{REFLEXIÓN FINAL.}

No podemos olvidar los grandes conjuntos de cerámica de otros museos o colecciones del país, entre los que destacamos el Museo Arqueológico Nacional, el Museo Nacional de Artes Decorativas, el Museo Nacional de Antropología, el Instituto Valencia de Don Juan, el Museo do Pobo Galego, el Museo de Artes y Tradiciones Populares de Sevilla, el Museo de Bellas Artes de Castellón y el Museo Provincial de Teruel.

El interés del público hacia la cerámica es realmente evidente, marcado en especial por la proximidad con la que se observa al producto, especialmente significativa en el caso de la alfarería. Se trata sin embargo de una proximidad basada en la cercanía de un material asequible, pequeño milagro de transformación de la materia de coste moderado que remite a imágenes de su uso cotidiano en la niñez. Sin embargo también se aprecian en él los valores de algo profundo, auténtico, con una estética peculiar y un misterio en su génesis que llama la atención incluso de los más jóvenes. Ello sin embargo no deja de manifestar la existencia de carencias en otros aspectos como son su valoración como bien esencial en la economía del pasado y las implicaciones que esto ha conllevado en el desarrollo de la sociedad. Este es el reto que deben asumir los museos de cerámica de hoy, aunar aspectos que atañen directamente a la sensibilidad con nociones que permiten comprender mejor la dimensión humana de este producto en sus innumerables vertientes, y también el camino que han empezado a desbrozar muchos de los museos especializados de nuestro país. 


\section{BIBLIOGRAFIA}

\section{-Museo Nacional de Cerámica.}

AMIGUES, F.; MESQUIDA, M.; SOLER. M.P. (1991) “La ceramica esgrafiada en los talleres mudéjares de Paterna (Valencia)". En Actas Congreso A Cerâmica Medieval no Mediterrâneo Ocidental, Campo arqueológico de Mértola, Mértola, 1991, pp. 305-314.

BORDON FERRER, M.; SOLER FERRER, M. P. (1997) “Pavimentos valencianos de los siglos XIV y XVI". En La céramique médiévale en Méditerranée (Aix-en-Provence 13-18 novembre 1995), AIECM2, Narration éditions, Aix-enProvence, 1997, pp. 667-675.

BRONCANO, S.; COLL CONESA, J. (1988) "Horno de cerámica ibérico de la Casa Grande (Alcalá del Júcar, Albacete)". Noticiario Arqueológico Hispánico, $\mathrm{n}^{\circ} 30,1988$, pp. 187-228.

CASANOVAS, M. A; COLL, J.; SOLER, M. P. (1997). “Catàleg”. En València -

Flandes. Ceràmica medieval. Valencia - Vlaanderen Middeleeuwse ceramiek.

Civitas Europa, Generalitat Valenciana, Valencia, 1997, pp. 80-225.

COLL CONESA, J. (1987). "Importaciones cerámicas bajomedievales en el valle de Sóller (Mallorca)”. En II Congreso de Arqueología Medieval Española. Vol. II. Pp. 357-373.

COLL CONESA, J. (1987). “Las Tejas Pintadas en el Valle de Sóller y Fornalutx (Mallorca). Análisis de las inscripciones". IV. CNACP. Etnología y Tradiciones Populares, Tom. II. Congreso de Zaragoza-Calatayud 1983, pp. 73-98.

COLL CONESA, J. (1987). “Ornamentación popular del tejaroz conquense”. En Etnología. Actas III Jornadas de Etnología de Castilla-La Mancha. Serv. de Publicaciones de la Junta de Comunidades de Castilla-La Mancha. Guadalajara (1985), pp. 11-28.

COLL CONESA, J. (1987). “Sobre Teules Pintades”. En ESTUDIS BALEARICS, vol. 24 Palma de Mallorca. Pp. 11-30.

COLL CONESA, J. (1989) “Del islam al cristianismo”. El Mundo del Regalo, 4, Cevider, Valencia, 1989, pp. 40-43.

COLl CONESA, J. (1990). “La Loza dorada de Manises en el Museo de Bellas Artes de Bilbao". Urtekaria, Museo de Bellas Artes de Bilbao, Bilbao, 1990, pp 29-37.

COLL CONESA, J. (1992). “La cerámica y las relaciones históricas y estéticas entre España y Portugal (siglos XIV al XIX)." Política Científica, n 34 , Comisión Intern. de Ciencia y Tecnología, Madrid, 1992, pp. 17-21. COLL CONESA, J. (1992). “El horno ibérico de Alcalá del Júcar. Reflexiones sobre los orígenes de la cocción cerámica en hornos de tiro directo y doble cámara en la Península Ibérica". En Tecnología de la cocción cerámica desde la antigüedad a nuestros días, Alicante, 1992, pp. 51-64.

COLL CONESA, J. (1993). "IX Fira del Fang. Algunes notes més sobre teules pintades". Portula, nº 127, Ajuntament de Marratxí, Palma de Mallorca, Abril 1993, 16 pp.

COLL CONESA, J. (1994). "Contenedores cerámicos medievales en las costas de Mallorca". En Actas del IV Congreso de Arqueología Medieval Española. Vol. III, (Alicante 1993), Asociación Española de Arqueología Medieval, Diputación de Alicante, 1994, pp. 1069- 1079.

COLL CONESA, J. (1994) “Aplicaciones Populares Ornamentales sobre Soporte Cerámico en la Arquitectura Española". En Schütz, Ilse (Coord.). Visión global y Acción Local. Global Denken - Lokal Handeln. Actas del IV Simposio de Investigación Cerámica y Alfarera (1993). Centro Agost de Investigación y Creación Cerámica y Alfarera, Agost, 1996, pp. 81-92. COLL CONESA, J. (1994). “Comentarios acerca de la alfarería femenina Magrebí. Conservadurismo y transformación en el sistema doméstico de producción cerámica". Forum Cerámico, $\mathrm{n}^{\circ} 2$, Asociación de Ceramología, Febrero 1994, Agost (Alicante), pp, 33-35.

COLL CONESA, J. (1994). “Museo Nacional de Cerámica y de las Artes Suntuarias 'González Martí'”. Cerámica y Vidrio, vol. 33, nº 6. Nov.Dic. 1994, pp. 337-339.

COLL CONESA, J. (1995). El azul en la loza de la Valencia medieval. Catálogo, Sala de Exposiciones de la Fundación Bancaja, Madrid, [1995], [8 pp.]. COLL CONESA, J. (1996). "Bibliografía histórica de la Cerámica Española: Programa BIHCE. Estado actual". En Cerámica y Vidrio, 35, fasc. 5, 1996, pp. 363-364.

COLL CONESA, J. (1996). “Recientes intervenciones de restauración de azulejería en arquitectura en España". En En actas XI Congreso de Conservación y Restauración de Bienes Culturales, Castellón, 1996.

COLL CONESA, J. (1996). Voz "Porcelana". Enciclopedia de la Arqueologia Industrial del País Valenciano, IVEI, València, 1996, p. 510-511. COLL CONESA, J. (1997). “11. Cerámica. La vasija rota. Utilidad y significado en la cerámica popular". En Etnología y Tradiciones de las Illes Balears. Ed. El Dia del Mundo, Palma de Mallorca, 1997, pp. 161-176.

COLL CONESA, J. (1998). “Desde la fotografía como memoria histórica a los bancos de datos gráficos para la investigación". En Museo, El museo: centro de documentación., APME, Madrid, 1998, pp. 121-129.

COLL CONESA, J. (1998). "Evolució dels forns ceràmics". En A la llum de la llar. Museu de Prehistòria, València, 1998, pp. 30-33.

COLL CONESA, J. (1998) “Cerámica moderna”. En Jiménez, Pedro; Navarro, Julio; Platería 14. Sobre cuatro casas andalusíes y su evolución (siglos X-XIII", Ayuntamiento de Murcia, Murcia,1998, pp. 51-64.

COLL CONESA, J. (1998). “Recubrimientos cerámicos en arquitectura. La problemática de su conservación en Valencia”. En Actas Qualicer'98, V Congreso Mundial de la calidad del azulejo y del pavimento cerámico, tom. II. Conferencias generales y Ponencias. Castellón, 1998.

COLL CONESA, J.; PEREZ CAMPS, J. (1994). “Aspectos de la técnica de fabricación en la cerámica de Manises (siglos XIV-XVI)". En Actas del IV Congreso de Arqueología Medieval Española. Vol. III, (Alicante 1993), Asociación Española de Arqueología Medieval, Diputación de Alicante. COLL CONESA, J.; VALTUEÑA, T.; DOMENECH, M. T; AURA, E. (1996). A propósito de la restauración de una salvilla de Alcora. Estudio analítico y aspectos tecnológicos. En actas XI Congreso de Conservación y Restauración de Bienes Culturales, Castellón, 1996.

COLL CONESA, Jaume; SCHUTZ, Ilse. (1997). “Die Fayence und ihre Vorläufer in “Al-Andalus". Keramos, heft 157, juli 1997, pp. 55-63. COLL CONESA, Je (1995). “Cerámica y evolución del patrón de asentamiento en el valle de Soller (Mallorca, Baleares) (s. IV al XII)." Actas del XXIII Congreso Nacional de Arqueología. Elx, Ajuntament d’Elx, 1995, vol. II, pp. 395-420.

COLL CONESA. J. (1996). “Cerámica y evolución del patrón de asentamiento en el valle de Sóller (Mallorca, Baleares) (ss. IV al XII)". En Actas del XXIII Congreso Nacional de Arqueología vol. II, (Elche, 1995), Elche, 1996, pp. 395420.

COLL, J.; SCHUTZ, I.; PEREZ CAMPS, J. (Coord.) (1992). Tecnología de la cocción cerámica desde la antigüedad a nuestros días. Asociación de Ceramología, Alicante, 1992, 237 pp.

COLL CONESA, J. PEREZ CAMPS, J. (1996). Bibliografía Histórica de la Cerámica Española (1988-1993). En Forum Cerámico, 6, 1996, Valencia, 68 p. COLL, J; PEREZ, J; SCHUTZ, I. (Coord.) (1994). Rehabilitación de la azulejería en la arquitectura. Asociación de Ceramología, Alicante, 223 p.

FALCAO, José Antonio; COLL CONESA, Jaume. (1988). "Fragmentos de azulejos mudéjares provenientes das ruinas do Convento de Nossa Senhora do Loreto (Santiago do Cacém)". Anais Da Real Soc. Arq. Lusitana, $2^{\mathrm{a}}$ ser, $2^{\circ}$ vol., Santiago do Cacém, 1988, pp. 91-102.

FALCAO, José Antonio; COLL CONESA, Jaume. (1992). O prato de Faiança seiscentista portuguesa do Museu Nacional de Cerâmica de Valência (Espanha). Trabalhos da Real Sociedade Arqueologica Lusitana II, Santiago do Cacem-Valência, 1992, 134 pp.

LERMA, J. V; SOLER, M.P. (1996). “Historia de la cerámica hispanomorisca de Manises". En El reflex de Manises. Cerámica hispanomorisca del Museu de Cluny de París (Catálogo de la exposición, maig-setembre 1996) Generalitat Valenciana, Consorci de Museus.

PAJUELO, Carlos. (1995). “La cerámica más bonita en el Museo González Martí". La Corriente, no 11, marzo 1995, pp. 26-27.

SOLER FERRER, María Paz (1984). Catálogo del Museo Nacional de Cerámica. Ministerio de Cultura, 1984. SOLER FERRER, María Paz (1988). Historia de la cerámica valenciana, vol. 2. Islam y cerámica mudéjar. Vicent García, Valencia, 1988, 270 pp.

SOLER FERRER, María Paz (1988). Historia de la cerámica valenciana, vol. 3.

Declive del siglo XVII, Renacimiento, Alcora y la azulejería del siglo XVIII. Vicent García, Valencia, 1988, 248 pp.

SOLER FERRER, María Paz (1989). “Cerámica española de los siglos XV y XVI". En Cerámica de los siglos XV y XVI. El mundo de las Antigüedades. Ed. Planeta Agostini, Barcelona, 1989, pp. 38-79.

SOLER FERRER, María Paz (1989). "Cerámica española del siglo XVIII". En Cerámica del siglo XVIII. El mundo de las Antigüedades. Ed. Planeta Agostini, Barcelona, 1989, pp. 56-79.

SOLER FERRER, María Paz (1990). “ VI. La cerámica con decoración de cuerda seca". En: La cerámica islámica en la ciudad de Valencia (II). Estudios. Ajuntament de València, Valencia, 1990, pp.97-114.

SOLER FERRER, María Paz (1992). "I. La loza manisera del XIX”. Historia de la Cerámica Valenciana, vol 4, Vicent García Editores, Valencia, 1992, pp. 7-120. SOLER FERRER, María Paz (1994). "Ceràmica valenciana en les col.leccions d'Ontinyent", 1994.

SOLER FERRER, María Paz (1996). “Obra daurada: els colors de l'or en la ceràmica valenciana. Museo de Bellas Artes, Valencia, 1996.

SOLER FERRER, María Paz (1997). “Pisa medieval valenciana." En València Flandes. Ceràmica medieval. Valencia - Vlaanderen Middeleeuwse ceramiek. Civitas Europa, Generalitat Valenciana, Valencia, 1997, pp. 25-54. SOLER FERRER, María Paz (1997). València-Nàpols. Les rutes mediterrànies de la ceràmica. Consorci de Museus de la Generalitat Valenciana. Valencia, 1997. 


\section{-Museo de Cerámica Ruiz de Luna.}

AMIGOS DEL MUSEO RUIZ DE LUNA (1994). “El nuevo museo de cerámica de Talavera". Cerámica y Vidrio, vol. 33, nº 6. Nov.Dic. 1994, pp. 341-344. CERAMICAS DE TALAVERA. Cerámicas de Talavera del siglo XVI al XX. (Cartel-catálogo de la exposición). Museo Numantino, Soria, 1994, [12 pp.]. GARCIA SERRANO, Rafael. “El Museo 'Ruiz de Luna' de Talavera de la Reina". Revista de Arqueología, año XVI, nº 183, Madrid, Z.E., Julio 1996. pp.48-55.

-Museo de Cerámica de Zaragoza (Sección del Museo Provincial). MUSEO DE ZARAGOZA (1988). La cerámica nos informa. Hoja de trabajo Museo de Zaragoza, Sección de Arqueología, Diputación General de Aragón, Zaragoza, 1988, 23 pp.

\section{-Museo de Cerámica de Barcelona.}

ALBERTI, Santiago (1990). "Inaguració del museu de ceràmica de Barcelona al nou emplaçament del Palau de Pedralbes". BUTLLETí INF-ORMATIU DE Ceràmica, $\mathrm{n}^{\circ} 46$, Associació Catalana de Ceràmica Decorada i Terrissa, Barcelona, 1990, pp. 24-31.

CASANOVAS, María Antonia (1989). “Prova de foc: Ceràmiques Galeria Fernando Alcolea". Butlletí Informatiu de Ceràmica, n ${ }^{\circ} 41$, Associació Catalana de Ceràmica Decorada i Terrissa, Barcelona, 1989, pp. 8-9.

CASANOVAS, M. A.; COLL, J.; SOLER, M. P.; VANDENBERGHE, S.; ZOZAYA, J. (1997). "Catàleg". En València - Flandes. Ceràmica medieval. Valencia - Vlaanderen Middeleeuwse ceramiek. Civitas Europa, Generalitat Valenciana, Valencia, 1997, pp. 80-225.

CASANOVAS, María Antonia (1984). La ceràmica catalana. La Llar del Llibre, Els llibres de la Frontera, Barcelona, 1984, 97 p.

CASANOVAS, María Antonia (1988). “Josep Serra Abella”. Butlletí Informatiu de Ceràmica, $\mathrm{n}^{\circ}$ 37, Associació Catalana de Ceràmica Decorada i Terrissa, Barcelona, 1988, pp. 4-5.

CASANOVAS, Maria Antonia (1988). "L'opció ceràmica de Benet Ferrer". Butlletí Informatiu de Ceràmica, $n^{\circ} 39$, Associació Catalana de Ceràmica Decorada i Terrissa, Barcelona, 1988, pp. 10-11

CASANOVAS, María Antonia (1988). "La ceràmica d'aplicació arquitectònica. Introducció històrica". PUBLICACIó ACC, n² 2, Associació Ceramistes de Catalunya, Olot (Girona), 1988, pp. 17-18.

CASANOVAS, María Antonia (1988). “Ramon Gausset, un ceramista fidel a la tradició. Exposició a la sala Rovira de Barcelona, gener 1988". Butlletí Informatiu de Ceràmica, n ${ }^{\circ} 36$, Associació Catalana de Ceràmica Decorada i Terrissa, Barcelona, 1988, 11 pp.

CASANOVAS, María Antonia (1989). Cerámica de Alcora en la colección del Banco Hispano-Americano. (Catálogo de la Exposición). Textos de M. A. Casanovas. Julio-agosto 1989, Torre de Don Borja, Santillana del Mar. Santillana del Mar, Fundación Santillana, 1989.

CASANOVAS, Maria Antonia (1992). "Mestre 'Murs Imaginaris". Publicació ACC, $n^{\circ}$ 8, Associació ceramistes de Catalunya, Barcelona, 1992, 4 pp.

CASANOVAS, María Antonia (1996). “Trascendencia de la Cerámica de Alcora en la Cerámica Española". En Schütz, Ilse (Coord.). Visión global y Acción Local. Global Denken - Lokal Handeln. Actas del IV Simposio de Investigación Cerámica y Alfarera (1993). Agost, 1996

CASANOVAS, Ma Antonia (1994). "Influencia de Alcora en otras manufacturas españolas". En Cat. Exp. El Esplendor de Alcora. 1994, Barcelona.

CASANOVAS, $\mathrm{M}^{\mathrm{a}}$ Antonia (1996). "La ceràmica de reflex daurat en la pintura de la segona meitat del segle XIX". En El reflex de Manises. Ceràmica hispanomorisca del Museu de Cluny de París (Catálogo de la exposición, maig-setembre 1996) Generalitat Valenciana, 1996.

GIRAL, Dolors; SANCHEZ-PACHECO, Trinidad. (1990). Picasso. Cerámicas y sus antecedentes malagueños. Catálogo de la exposición. Málaga, Fundación Picasso, 1990

GIRAL, María Dolors (1989). "Maria Bofill”. Butlletí Informatiu de Ceràmica,

n 40, Associació Catalana de Ceràmica Decorada i Terrissa, Barcelona, 1989,

pp. 5-7.

GIRAL, María Dolors (1990). "Núria Pié, el passat més contemporani". BUTLLETí InfORMATIU DE Ceràmica, $n^{\circ}$ 45, Associació Catalana de Ceràmica Decorada i Terrissa, Barcelona, 1990, pp. 30-31.

GIRAL, Maria Dolors. (1991). “La secció contemporània del museu de ceràmica de Barcelona". Butlletí Informatiu de Ceràmica, n 50, Associació Catalana de Ceràmica Decorada i Terrissa, Barcelona, 1991, pp. 11-13.

MUSEU DE CERAMICA DE BARCELONA (1988). Guía del Museo de Cerámica. Ayuntamiento de Barcelona, Barcelona, 1988, 116 pp MUSEU DE CERAMICA DE BARCELONA (1992). Resum de les activitats de l'any 1991. Museu de Ceràmica de Barcelona. Barcelona, Ajuntament, D.L. 1992. [24] pp. :il.

SANCHEZ PACHECO, T.; CASANOVAS, M.A.; GIRAL, M. D. (1993). Museo de Cerámica. Palacio de Pedralbes Barcelona. Col. Monumentos y Museos.
IberCaja, Gante, Barcelona, 1993, 104 pp.

SANCHEZ PACHECO, T.; CASANOVAS, M.A.; GIRAL, M. D. (1993). Museo de Cerámica. Palacio de Pedralbes Barcelona. Col. Monumentos y Museos. IberCaja, Gante, Barcelona, 1993, 104 pp.

SANCHEZ PACHECO, T.; CASANOVAS, M.A.; GIRAL, M. D. (1993). Museo de Cerámica. Palacio de Pedralbes Barcelona. Col. Monumentos y Museos. IberCaja, Gante, Barcelona, 1993, 104 pp.

SANCHEZ PACHECO, T.; CASANOVAS, M.A.; GIRAL, M. D. (1993). Museo de Cerámica. Palacio de Pedralbes Barcelona. Col. Monumentos y Museos. IberCaja, Gante, Barcelona, 1993, 104 pp.

SANCHEZ PACHECO, Trinidad (1989). Picasso nella ceramica. (Catálogo de la Exposición). [Exposición 1-30 noviembre 1989, Viterbo] a cura di Trinidad Sánchez Pacheco. Viterbo : FAVL, cop. 1989,103 pp. 33 lám.

SANCHEZ PACHECO, Trinidad (1992). "Loza mudéjar”. Galería Antiquaria, $\mathrm{n}^{\mathrm{o}}$ 101, Madrid, diciembre de 1992, pp. 32-42.

SANCHEZ PACHECO, Trinidad (1996). "Precedents de la pisa mudéjar valenciana: Orient i al-Andalus". En El reflex de Manises. Ceràmica hispanomorisca del Museu de Cluny de París (Catálogo de la exposición, maig-setembre 1996) Generalitat Valenciana, Consorci de Museus, 1996.

SANCHEZ PACHECO, Trinidad. (1993) "El mundo cerámico de Joan Miró". En Miró Ceramista. Exp. Museu de Ceràmica, Ajuntament de Barcelona. Barcelona, Ed. Electa, 1993, pp. 11-16.

\section{-Museu de Cerámica de Manises.}

BERROCAL RUIZ, P.; PEREZ CAMPS, J.; ALGARRA, V. M. (1992)

"Pervivencia funcional del barrio de "Obradors" en Manises: la fábrica de cerámica "Palés S.L." como modelo". Butlletí Assoc. Valenciana d'Arqueología Industrial, $\mathrm{n}^{\circ}$ 2, València, 1992, primavera-estiu, 5 pp.

BOTELLA, Pablo; PEREZ CAMPS, José; LARENA, M. Teresa (1996).

"Caracterización química de las fritas de la cerámica de Manises del siglo XV". XXXVI Congreso Nacional de Cerámica y Vidrio. Libro de resúmenes. San Sebastián, 1996, 38 pp.

COLL CONESA, J, y PEREZ CAMPS, J. (1994). “Aspectos de la técnica de fabricación en la cerámica de Manises (siglos XIV-XVI)", en IV Congreso de Arqueología Medieval Española (Alicante, 1993). Asociación Española de Arqueología Medieval, 1994, Madrid.

COLL CONESA, J. PEREZ CAMPS, J. (1996). Bibliografía Histórica de la Cerámica Española (1988-1993). En Forum Cerámico, 6, 1996, Valencia, 68 p. COLL CONESA, J.; PEREZ CAMPS, J. (1994). “Aspectos de la técnica de fabricación en la cerámica de Manises (siglos XIV-XVI)”. En Actas del IV Congreso de Arqueología Medieval Española. Vol. III, (Alicante 1993), Asociación Española de Arqueología Medieval.

COLL, J.; SCHUTZ, I.; PEREZ CAMPS, J. (Coord.) (1992). Tecnología de la cocción cerámica desde la antigüedad a nuestros días. Asociación de Ceramología, Alicante, 1992, 237 pp.

PEREZ CAMPS, Josep (1989). “Enric Mestre a Alcoi”. Enric Mestre. Mostra retrospectiva de Ceràmica. Centre Municipal de Cultura , Alcoy, 1989, pp. 3-4 PEREZ CAMPS, Josep (1990). “Recipients ceràmics relacionats amb les olives l'oli a la comarca del Comtat". L'OLIVERA i L'OLI AL CoMTAT, Centre d'Estudis Contestans, Cocentaina, 1990, pp. 179-198.

PEREZ CAMPS, Josep (1990). “Col.leccions singulars del Museu de Ceràmica de Manises. 1/ La Ceràmica política de Manises en el primer terç del segle XX". MANISES, nº de noviembre, Ajuntament de Manises, Manises, 1990, pp. 26-29. PEREZ CAMPS, Josep (1991). “Col.leccions singulars del Museu de Ceràmica de Manises. 2/ Filtres i Sinaís". MANISES, nº de febrero, Ayuntamiento de Manises, Manises, 1991, pp. 36-39.

PEREZ CAMPS, Josep (1991). “Col.leccions singulars del Museu de Ceràmica de Manises. 3/. Les botiges de fantasia". MANISES, $n^{\circ}$ de mayo, Ayuntamiento de Manises, Manises, 1991, pp. 24-27.

PEREZ CAMPS, Josep (1991). “Col.leccions singulars del Museu de Ceràmica de Manises. 4/ La vaixella popular en la primera meitat del segle XX". MANISES, Ajuntament de Manises, Manises, octubre de 1991, pp. 20-23. PEREZ CAMPS, Josep (1992). "Col.leccions singulars del Museu de Ceràmica de Manises. 5/ Reproduccions contemporànies del gerro de l'Alhambra". MANISES, Ajuntament de Manises, Manises, febrer de 1992, pp. 19-22. PEREZ CAMPS, Josep (1992). "Col.leccions singulars del Museu de Ceràmica de Manises. 6/ Fàbriques de ceràmica a Manises en el primer terç del segle XX". MANISES, Ajuntament de Manises, Manises, juny de 1992, pp. 19-22. PEREZ CAMPS, Josep (1992). "La cerámica valenciana en el siglo XX”. Historia de la cerámica valenciana , t. IV, Vicent García, Valencia, 1992, pp. 121-285. PEREZ CAMPS, Josep (1993). “Artesanía e industria cerámica en el País Valenciano durante la primera mitad del siglo XX". Forum Cerámico, $\mathrm{n}^{\circ} 1$, Asociación de Ceramología, Valencia, 1993, 38 p.

PEREZ CAMPS, Josep (1993). “El ceramista Juan Bautista Huerta (Manises 1878-1949)". Revista de Festes, Clavaris de Santas Justa y Rufina, Manises, 1993, pp. 88-95.

PEREZ CAMPS, Josep (1994). “Apostillas a "Artesanía e industria cerámica en el País Valenciano durante la primera mitad del siglo XX". Forum Cerámico, ${ }^{\circ}$ 
2, Valencia, 1994, $38 \mathrm{pp}$.

PEREZ CAMPS, Josep. (1994). “La producción tinajera de villarrobledo en 1959, según la recopilación de datos conservados en el archivo de Alfons Blat". Forum Cerámico , nº 3, Asociación de Ceramología, Julio 1994, Agost (Alicante), pp, 14-22.

PEREZ CAMPS, Josep (1995). “La cerámica valenciana y los paneles devocionales de las Santas Justa y Rufina conservados en Agost, Manises y Valencia”. Forum Cerámico , nº, Asociación de Ceramología, 1995, Agost (Alicante), pp, 54. PEREZ CAMPS, Josep (1995). "Plafons devocionals de les Santes a Agost, Manises y Valencia". Manises'95 Festes Patronals. Manises, Clavaria de les Santes Escudelleres. Festes Patronals de Manises, 1995. Pp. 106-113.

PEREZ CAMPS, Josep (1996). “La Cerámica de Manises antes y después de la Fundación de la Fábrica de Alcora". En Schütz, Ilse (Coord.). Visión global y Acción Local. Global Denken - Lokal Handeln. Actas del IV Simposio de Investigación Cerámica y Alfarera, Agost, 1996.

PEREZ CAMPS, Josep (1998). La ceràmica de reflex metal.lic a Manises 19801960. Col. Ethnos, Museu d'Etnologia de la Diputació de València. Centre Cultural de la Beneficencia. Valencia, 1998.

\section{-Museo de Cerámica de Paterna.}

AMIGUES, François; MESQUIDA, Mercedes (1990). “Tradición alfarera en Paterna. Pasado y presente". En Fours de Potiers et "testares" médiévaux en Mediterranée Occidentale. Méthodes et résultats. Madrid, Casa de Velázquez, Serie Archéologie XIII, 1990, pp.

AMIGUES, F.; MESQUIDA, M.; SOLER. M.P. (1991) “La ceramica esgrafiada en los talleres mudéjares de Paterna (Valencia)". En Actas Congreso A Cerâmica Medieval no Mediterrâneo Ocidental, Campo arqueológico de Mértola, Mértola, 1991, pp. 305-314.

AMIGUES, François; MESQUIDA, Mercedes (1993). Les ateliers et la céramique de Paterna (XIIIe-XVè siècle). Cat. exposición 22/7 al 30/10. Musée Saint Jacques. Ville de Béziers, Béziers, 1993, 72 p.

AMIGUES, François; MESQUIDA, Mercedes (1995). "Las alfarerías medievales de Paterna: técnicas de fabricación". En Actes du 5ème Colloque sur la Céramique Médiévale (Rabat 11-17 Novembre 1991), Rabat, 1995. MESQUIDA GARCIA, Mercedes (1988). "Alfares medievales de Paterna". Revista de Fiestas, Paterna, 1988, s.p. [3 pp.].

MESQUIDA GARCIA, Mercedes (1989). La ceràmica de Paterna al segle XIII. Ayuntamiento de Paterna, Paterna, 1989, 30 pp.

MESQUIDA GARCIA, Mercedes (1990). “Candelers i cresols medievals / Lámparas y candiles medievales". En Candelers i cresols medievals. Ajuntament, Paterna, 1990, pp. 4-53.

MESQUIDA GARCIA, Mercedes (1992). “La cocción de cerámica en un horno medieval". En Tecnología de la cocción cerámica desde la antigüedad a nuestros días, Alicante, 1992, pp. 121-140.

MESQUIDA GARCIA, Mercedes (1992). “El bestiario en la cerámica de Paterna". ARS LONGA, n 3, Departamento de Historia del Arte, de la Universidad de Valencia, Valencia, 1992, pp. 77-95.

MESQUIDA GARCIA, Mercedes (1997). “Cerámica de uso arquitectónico fabricada en Paterna”. En La céramique médiévale en Méditerranée (Aix-enProvence 13-18 novembre 1995), AIECM2, Narration éditions, Aix-en-Provence, 1997, pp. 655-666.

MESQUIDA GARCIA, Mercedes (1996). “Paterna en el Renacimiento.

Resultado de las excavaciones de un barrio burgués. Ayuntamiento de Paterna, 1996, 150 p. 10 láms.

MESQUIDA GARCIA, Mercedes (1998). “Els aliments a l'edat Mitjana: la seua conservació". 2as. Jornades d'Història d'Alboraia. Ajuntament d'Alboraia, maig 1998, pp. 207-226.

MESQUIDA GARCIA, Mercedes; VILLALOBOS TORVISCO, Rosa (1990).

Candelers i cresols medievals. Ajuntament, Paterna, 1990, 59 pp.

MUSEU MUNICIPAL DE CERAMICA (Paterna) (1990). Museu Municipal de Cerámica. Ajuntament, Paterna, 1990, 1 p.

\section{-Museu de Terrissa de La Bisbal.}

CASADEMONT I FERRIOL, Dolors (1991). Lluis Cornellá: Anàlisi d'un procés de fer negre. Ajuntament de la Bisbal, La Bisbal d'Empordà, 1991, 24 pp. ROSAL, Joan; CASADEMONT, Dolors (1991). “L'obra negra de la Bisbal. $3^{\mathrm{a}}$. part”. Butlletí Informatiu de Ceràmica, nº 48, Associació Catalana de Ceràmica Decorada i Terrissa, Barcelona, 1991, pp. 24-27.

\section{-Museu d'Onda.}

AJUNTAMENT D'ONDA (1996). Escenes de la vida de Crist segons Ismael Mundina. Eremitori de El Salvador, Onda, Agost 1996. Textos de V. Estall y I. Sansano. Onda, Ajuntament, 1996, 6 pp.

ESTALL I POLES, Vicent Joan (1994). "(Eco)Museo de la cerámica de Onda”. Cerámica y Vidrio, vol. 33, nº 6. Nov.Dic. 1994, pp. 349-352.

ESTALL I POLES, Vicent Joan (1997). La industria ceràmica en Onda. Las fábricas, 1778-1997. Monografías del Museo del Azulejo de Onda, I.
Ajuntament d'Onda, 1997, 102 p.

FELIU, J. “ El Modernismo en la cerámica arquitectónica valenciana. El caso de Onda, 1890-1950”. La Plana, Nules, IV Congreso de Historia y Filología,

Diputación de Castellón, 1996.

CERAMICA INFORMACION (1998). "Museo de Onda. Un centro intercativo para el siglo que viene". Cerámica Información, 239, 1998.

-Museu de l'Alcora.

AJUNTAMENT DE L'ALCORA (1996). Museu de Ceràmica. L'Alcora. Guia. Ajuntament de l'Alcora, Alcora, 1996, 20 pp.

GRANGEL, Eladio (1994). La cerámica artística de Alcora. Desde el Conde de Aranda hasta nuestros días. Cerámica y Vidrio, vol. 33, nº 6. Nov.Dic. 1994, pp. $345-348$.

\section{-Museu de l'Enrajolada y Memorial Ros.}

ALCOBE, Margarita; GARCIA, Salvador (1992). “Arranque de los azulejos del Museu Municipal Vicenç Ros y Memorial Museu Vicenç Ros de Martorell (Barcelona), e instalación de un nuevo soporte". En IX Congreso de Conservación y Restauración de Bienes Culturales, Sevilla, 1992, pp. 387-402. ALCOBE, Margarita; GARCIA, Salvador (1995). “La azulejería de los museos de Martorell (Barcelona): Museu Municipal Vicenç Ros, Memorial Museu Vicenç Ros i l'Enrajolada". En Coll, Pérez \& Schutz (coord.). Rehabilitación de la azulejería en la arquitectura. Asociación de Ceramología. Agost, 1995, pp. 201-222.

\section{-Museo de Alfarería de Agost.}

CHINCHILLA, Clarisa; SCHÜTZ, Ilse (1996). "Montemos el Belén. Una experiencia didáctica con alumnos de $8^{\circ}$ curso del Colegio La Milagrosa de Agost" Oficio y Arte, junio-julio 1996,10 pp.

COLL CONESA, J. ; SCHÜTZ, I. (1996). “Die Fayence und Ihre Vorläufer in 'Al-Andalus'". En Keramos. Num. 157. Julio 1997. pp. 55-63.

LAVADO, Pedro; SCHUTZ, Ilse (1988). "Der didaktische Koffer MEC-1". Töpferei und keramikforschung. Band 1. Dr. Rudolf Halbert GMBH, Bonn, 1988, pp. 172-182.

MAMPEL, Uwe; SCHUTZ, Ilse (1988). "Die Töpferöfen von Agost”. Neue Keramik, n 3, 1988, pp. 114-115.

SCHÜTZ, Ilse (1988). "Aufbau eines Töpfereimuseums im Töpferzentrum Agost, Alicante, Spanien". Töpferei und keramikforschung. Band 1. Dr. Rudolf Halbert GMBH, Bonn, 1988, pp. 160-171.

SCHÜTZ, Ilse (1991). La loza de Biar. Cerámica valenciana. (Catálogo de la Exposición). Julio-Septiembre 1991, Museo de Alfarería de Agost, Alicante / Ilse Schütz. Agost, Alicante : Centro Agost, Museo de Alfarería, D.L. 1991. 75 pp.

SCHÜTZ, Ilse (1992). “Sistemas tradicionales de cocción cerámica en el Norte de Africa". En Tecnología de la cocción cerámica desde la antigüedad a nuestros días, Alicante, 1992, pp. 153-170.

SCHÜTZ, Ilse (1992). “La cocción cerámica en la alfarería tradicional de Agost". En Tecnología de la cocción cerámica desde la antigüedad a nuestros días, Alicante, 1992, pp. 171-184.

SCHÜTZ, Ilse (1992). Fang '92. La alfarería actual de Agost. (Catálogo de la exposición). Centro Agost/Museo de Alfarería, Agost, 1992, 40 pp.

SCHÜTZ, Ilse (1992). Cántaros Valencianos. Centro Agost/Museo de Alfarería, Agost, 1992, 16 pp.

SCHÜTZ, Ilse (1993). "De alfareros, olleros y plateros o buceando en el Archivo Municipal de Biar". Festes de Maig. Moros i cristians en honor a la Mare de Déu de Gràcia, Ajuntament de Biar, Biar, 1993, pp. 101-108.

SCHÜTZ, Ilse (1993). "La mujer en la alfarería española”. LA MUJER EN LA ALFARERíA ESPAÑOLA. Centro Agost/ Museo de Alfarería, Alicante, 1993, pp. 8-10.

SCHÜTZ, Ilse (1993). "Dos mujeres como patronas del oficio". LA MUJER EN LA ALFARERíA ESPAÑOLA. Centro Agost/Museo de Alfarería, Alicante, 1993, pp. 12-13.

SCHÜTZ, Ilse (1993). “La alfafería femenina”. LA MUJER EN LA ALFARERíA ESPAÑOLA. Centro Agost/Museo de Alfarería, Alicante, 1993, pp. 13-15. SCHÜTZ, Ilse (1993). "La mujer en la alfarería masculina". LA MUJER EN LA ALFARERíA ESPAÑOLA. Centro Agost/Museo de Alfarería, Alicante, 1993, 24 pp.

SCHÜTZ, Ilse (1993). "La mujer como esposa o hija del dueño alfarero". LA MUJER EN LA ALFARERíA ESPAÑOLA. Centro Agost/Museo de Alfarería, Alicante, 1993, pp. 25-26. SCHÜTZ, Ilse (1993). “El modelado a torno rápido: Dolores Coronado Velázquez, (Ocaña)”. LA MUJER EN LA ALFARERíA ESPAÑOLA. Centro Agost/Museo de Alfarería, Alicante, 1993, 28 pp. SCHÜTZ, Ilse (1993). “La participación de la mujer en la alfarería a torno rápido: Ejemplo Agost (Alicante)". LA MUJER EN LA ALFARERíA ESPAÑOLA. Centro Agost/Museo de Alfarería, Alicante, 1993, pp. 29-32. SCHÜTZ, Ilse (1993). "La mujer como vendedora, la tía Genoveva de Agost (Alicante)". LA MUJER EN LA ALFARERíA ESPAÑOLA. Centro Agost/ Museo de Alfarería, Alicante, 1993, pp. 36-39. 
SCHÜTZ, Ilse (1993). “La mujer como consumidora”. LA MUJER EN LA ALFARERíA ESPAÑOLA. Centro Agost/Museo de Alfarería, Alicante, 1993, pp. 40-41. SCHÜTZ, Ilse (1993). “Resumen”. LA MUJER EN LA ALFARERíA

ESPAÑOLA. Centro Agost/Museo de Alfarería, Alicante, 1993, pp. 42-43.

SCHÜTZ, Ilse (1993). "Jesus im Dutzend billiger. Tonfiguren aus Murcia".

Nearchos, nº 1, 1993, pp. 235-245.

SCHÜTZ, Ilse (Coord.) (1993). La mujer en la alfarería española. Centro Agost/Museo de Alfarería - Agost (Alicante). Cat. Exposición Colegio Oficial de Arquitectos, Alicante, 1993, 55 pp.

SCHUTZ, Ilse (1994). "Anotaciones complementarias en torno a los datos sobre artesanía e industria cerámica en el País Valenciano durante la primera mitad del siglo XX". Forum Ceramico, nº 2, Valencia, 1994, pp 36-37. SCHÜTZ, Ilse (1994). "Con las Alfareras de Slit, Marruecos". Forum Cerámico $n^{\circ}$ 2, Asociación de Ceramología, Febrero 1994, Agost (Alicante), pp, 5-13. SCHÜTZ, Ilse (1995). "Santas y Santos patronos de los alfareros". Forum Cerámico , nº, Asociación de Ceramología, 1995, Agost (Alicante), pp, 51-53. SCHUTZ, Ilse; VERGARA, Antonio (1995). Cántaros valencianos.

Ayuntamiento de Vinarós, Museo de Vinarós, s.d. [1995], 24 pp.

SCHUTZ, Ilse (Coord.) (1996). Visión global y Acción Local. Global Denken Lokal Handeln. Actas del IV Simposio de Investigación Cerámica y Alfarera (1993). Centro Agost de Investigación y Creación Cerámica y Alfarera, Agost, 1996, pp. 11-16.

SCHUTZ, Ilse (1996). “Motivos y Consecuencias de los Cambios Tecnológicos en la Alfarería Tradicional de Agost". En Schütz, Ilse (Coord.). Visión global y Acción Local. Global Denken - Lokal Handeln. Actas del IV Simposio de Investigación Cerámica y Alfarera (1993). Centro Agost de Investigación y Creación Cerámica y Alfarera, Agost, 1996, pp. 101-105.

SCHUTZ, Ilse (1996). "Biar: de la Alfarería de Ollas y Cántaros a la loza fina". En Schütz, Ilse (Coord.). Visión global y Acción Local. Global Denken - Lokal Handeln. Actas del IV Simposio de Investigación Cerámica y Alfarera (1993).
Centro Agost de Investigación y Creación Cerámica y Alfarera, Agost, 1996, pp. 129-133.

-Museo de Ollerías (Elosu, Alava).

GOMEZ DE SEGURA, Blanca (1994). "La ceramica popular vasca." Artisautza, $\mathrm{n}^{\circ}$ 6, 1994, pp. 6-9.

OLLERIASKO EUSKAL BUZTINGINTZA MUSEOA (1997). Euskal Herriko eltzegindegi tradizionalak XX. Mendean. Eusko Jaurlaritza. Thardun Multimedia. 1997. (CD-Rom multimedia, bilingüe vasco-castellano).

-Museo de Ubeda.

SEMPERE FERRANDIZ, Emili (1993). “Un terrisser crea el primer museu de terrissa d'Andalusia". Butlletí Informatiu de Ceràmica, n ${ }^{\circ}$ 2, A.C.C.D.T., Barcelona, 1993, pp. 16-17.

-Museo de Cerámica Nacional de Chinchilla.

SANCHEZ FERRER, José (1989).

El alfar tradicional de Chinchila de Montaragón. Inst. Est. Albacetenses, Albacete, 1989.

USEROS, Carmina (1984). "La artesanía en España". Boletín del Cultural Albacete, 13, 1985.

USEROS, Carmina; BELMONTE, Manuel (1984).

"La artesanía popular albacetense".

Boletín del Cultural Albacete, 11, 1984.

-Museo de la Cerámica y los relojes Basilio Sobrecueva (Cangas de Onís). MUSEO DE LA CERAMICA Y LOS RELOJES

BASILIO SOBRECUEVA (1997). La alfarería y la cerámica en Asturias. Museo de la Cerámica y los Relojes Basilio Sobrecueva, Cangas de Onís, 1997, s.p.

-Museo de los Molinos (Valdepeñas).

MUSEO DE LOS MOLINOS (1997). Jornadas sobre la alfarería. Museo de los

- - molinos Gregorio Prieto y Ciudad de Valdepeñas. Valdepeñas, 1997, 33 p.

-Museo Os Oleiros (Os Oleiros, A Coruña).

KAYDEDA, José María (1995). Museo Os Oleiros. Concello Os Oleiros, 1995. 